\title{
TECHNOLOGY DEVELOPMENTS FOR AN ADVANCED L-BAND RADIOMETER MISSION
}

\author{
Manuel Martin-Neira ${ }^{1}$, Martin Suess ${ }^{1}$, Nikos Karafolas ${ }^{1}$, Petri Piironen ${ }^{1}$, François Deborgies ${ }^{1}$, \\ Albert Catalán' ${ }^{2}$ Roger Vilaseca', José Montero ${ }^{2}$, Montserrat Puertolas 2 , Diego Outumuro', \\ Ignasi Corbella ${ }^{3}$ Israel Durán ${ }^{3}$, Nuria Duffo ${ }^{3}$, Roberto Materni,$$
\text { Teresa Mengual }{ }^{5} \text {, Miguel Angel Piqueras }{ }^{5} \text {, Pablo Villalba }{ }^{5} \text {, }
$$ \\ Ana Olea ${ }^{6}$, Andrés Solana ${ }^{6}$, Josep Closa ${ }^{6}$, Albert Zurita ${ }^{6}$, Juan Ignacio Ramirez ${ }^{6}$, \\ Olav Breinbjerg ${ }^{7}$, Jeppe Majlund Bjørstorp ${ }^{7}$, Kyriakos Kaslis ${ }^{7}$, Steen Savstrup Kristensen ${ }^{7}$, \\ Roger Oliva ${ }^{8}$, Raúl Onrubia ${ }^{8}$, Adriano Camps $^{3}$, Jorge Querol ${ }^{9}$ \\ ${ }^{I}$ European Space Agency, ESTEC, Noordwijk, The Netherlands \\ ${ }^{2}$ SENER Aeroespacial, Spain \\ ${ }^{3}$ Polytechnic University of Catalonia, Barcelona, Spain \\ ${ }^{4}$ Saphyrion Sagl, Bioggio, Switzerland \\ ${ }^{5}$ DAS Photonics, Valencia, Spain \\ ${ }^{6}$ Airbus Defence and Space, Madrid, Spain \\ ${ }^{7}$ Technical University of Denmark, Lyngby, Denmark \\ ${ }^{8}$ Zenithal Blue Technologies, Barcelona, Spain \\ ${ }^{9}$ MITICS, Barcelona, Spain
}

\begin{abstract}
ESA's Soil Moisture and Ocean Salinity (SMOS) mission was launched 2 Nov 2009 and, to date, is still in good health, providing valuable L-band observations of the Earth surface [1]. A number of products are obtained from these, including thin sea ice [2], frost/thaw soils [3], high winds [4], ocean surface wind [5] and Sun brightness temperature [6], besides the main mission measurements of soil moisture and sea surface salinity [7][8]. This paper deals with the description and early results of some technology activities conducted by ESA applying the lessons learnt by SMOS and in preparation of an advanced L-band radiometer mission.
\end{abstract}

Index Terms - SMOS, MIRAS, L-band receivers, optical harness, correlator

\section{INTRODUCTION}

SMOS is producing, as main data products, global maps of soil moisture and sea surface salinity, at an average spatial resolution of $40 \mathrm{~km}$ and a revisit time of 3 days. As of 11 June 2019, the measurements from ESA's SMOS mission are being fully integrated into forecasting system of the European Center for Medium-Range Weather Forecasts (ECMWF), allowing for a more accurate description of water content in soil [9]. Its current life-time exceeding 10 years has allowed the generation of additional products and the use of SMOS data in practical applications related to food supply, flood forecasting, severe weather monitoring, ocean circulation, sea ice mapping, methane cycle and space weather. The different user communities that benefit from SMOS data, and, in general, from L-band observations from space, as those also provided by NASA's Aquarius and SMAP missions, and the future ESA's CIMR mission, expressed their wishes and requirements for a future L-band operational mission at a workshop in ECMWF in December 2017 [10]. The main user wish, with highest priority, was to ensure data continuity in the provision of L-band measurements, with a concluding recommendation of improving sensitivity and spatial resolution beyond those of currently flying missions (SMOS and SMAP), with a $10 \mathrm{~km}$ goal.

This paper addresses the results of internal activities and industrial contracts, some completed, some on-going, in preparation of a future advanced L-band radiometer mission which could achieve the wishes and, eventually, the goal requirement of $10 \mathrm{~km}$ spatial resolution, of the scientific communities using this type of observations.

\section{KEY LESSONS LEARNT FROM SMOS}

An important lesson learnt from SMOS is that the purely passive band $1400-1427 \mathrm{MHz}$ is extensively polluted from Radio-Frequency Interference (RFI), and also the need to ensure compliance with the ITU Radio-Regulations given that all emissions in this band are prohibited (RR No 5430). Malfunctioning equipment, some mass-market surveillance systems, unauthorised broadcasting stations and radio-links, or terrestrial wired-system with poor isolation produce illegal emissions inside the protected band. In addition, active 
systems operating in the bands adjacent to $1400-1427 \mathrm{MHz}$ (i.e. typically radar systems) may also cause RFI in the protected band due to their excessive out-of-band emissions. ESA and NASA have been very concerned with the problem of RFI at L-band, having impact in several Earth Observation missions such as SMOS, SMAP and Aquarius. Both agencies have joined efforts to report to the different administrations the cases of harmful interference detected over their territories. Thanks to the cooperation of the National Regulatory Authorities, more than 400 RFI sources have already been successfully identified and switched-off since early 2010. Such effort should be maintained and also continued by any future L-band radiometry mission, in addition of RFI filtering implemented on board.

Another important result of SMOS, related to RFI, is the need to reduce the instrument side lobes. Any RFI excites secondary lobes that contaminate many image pixels. In aperture synthesis, sidelobe level is intrinsically linked to the shape of the array: an hexagonal array has much lower sidelobes than a Y-shape interferemeter as SMOS, being thus the preferred geometry to limit the RFI spread across the image. In practice, however, the sidelobe level is further dependent on system imperfections, in particular, on the similarity among the embedded antenna patterns of the array elements. To equalize these, dummy elements can be placed next to the active ones (Fig.1). In turn, more similar patterns lead to less image spatial ripple.

Regarding swath width, the reduced incidence angle range towards the edges of the alias-free field of view affects the quality of the data products. A future mission should ensure a larger field of view in order to increase the range of incidence angle over a wider swath. This is possible by reducing the spacing between antenna elements.

Another relevant lesson from SMOS is that there is no need to embark dedicated noise injection radiometers to measure the zero-spacing baseline. Instead, the average of the system temperature measured by all the array elements (total power radiometers) can be used.

\section{ADVANCED INSTRUMENT ARCHITECTURE}

Taking into account the key lessons learnt from SMOS and the user requirements set out in the mentioned ECMWF workshop [10], formulated more detailed in a white paperon L-band radiometry for earth observation [11], this section describes the architecture of an advanced instrument which would be a stepping stone towards the fulfilment of those.

First of all, the array would be hexagonal, having the elements with a smaller spacing $(0.707 \lambda)$ than in SMOS $(0.875 \lambda)$, achieving a larger incidence angle range over a wider swath (Fig.2). Moreover, the field of view would become large enough that the instrument could be pointed straight to nadir instead of $32.5^{\circ}$ forward as SMOS (Fig.3). The combination of the hexagonal shape of the array and the nadir pointing would result in a $26.6 \mathrm{~km}$ spatial resolution at

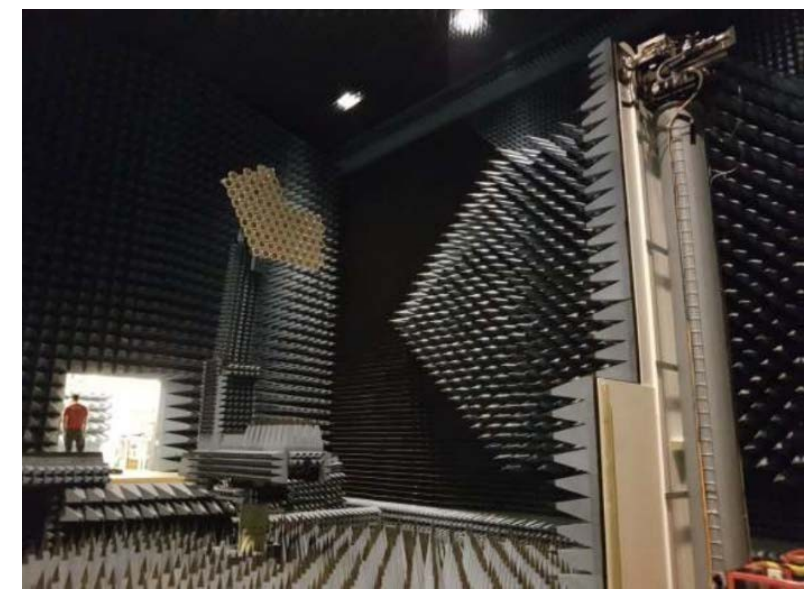

Figure 1 - Measurement of embedded patterns using the dummy element technique at the DTU antenna range

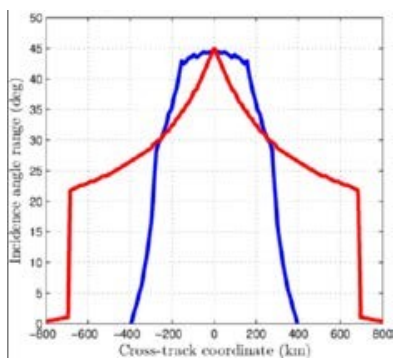

Figure 2 - range of incidence angles (maximum minus minimum) as a function of cross-track distance for SMOS (blue) and the advanced L-band radiometer (red)
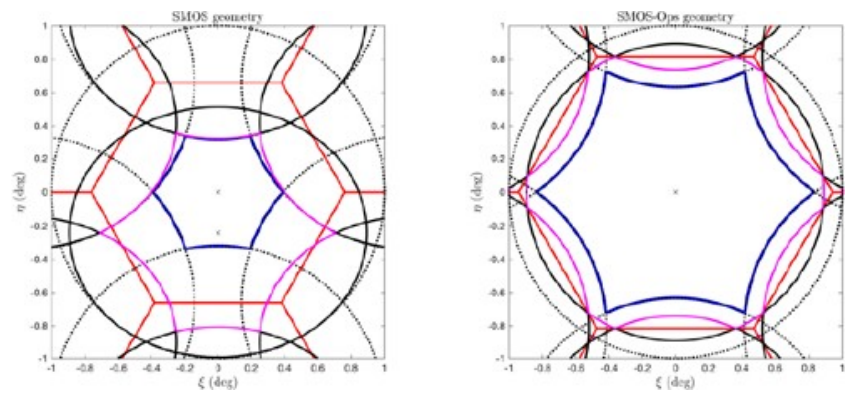

Figure 3 - SMOS (left, $32.5^{\circ}$ tilt) and advanced L-band radiometer (right, $0^{\circ}$ tilt) field of view: alias-free $\mathrm{FoV}$ (blue), extended AF-FoV (magenta), reconstruction hexagon (red), unit circle and aliases (dashed black), Earth contour and aliases (solid black), nadir and boresight (cross)

boresight (40.6 km in SMOS). A roadmap on how to reach the more demanding $10 \mathrm{~km}$ is given later in the paper.

The larger number of antennas in the hexagonal array than in the Y-shaped SMOS outweighs the smaller collecting area of each one, which would result in a net improvement in sensitivity. To enhance the sensitivity further, the advanced L-band instrument would receive both polarizations, horizontal $\mathrm{X}$ and vertical $\mathrm{Y}$, in parallel. In SMOS the receivers switch between $\mathrm{X}$ and $\mathrm{Y}$ sequentially.

To filter out RFI, the correlator on-board in charge of the interferometric processing would implement techniques to 

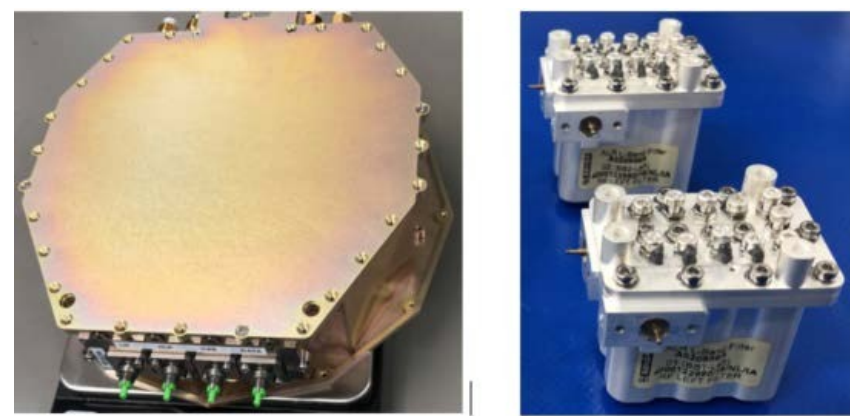

Figure 4 - Advanced L-band Receiver (left) and band-pass cavity filters (right)

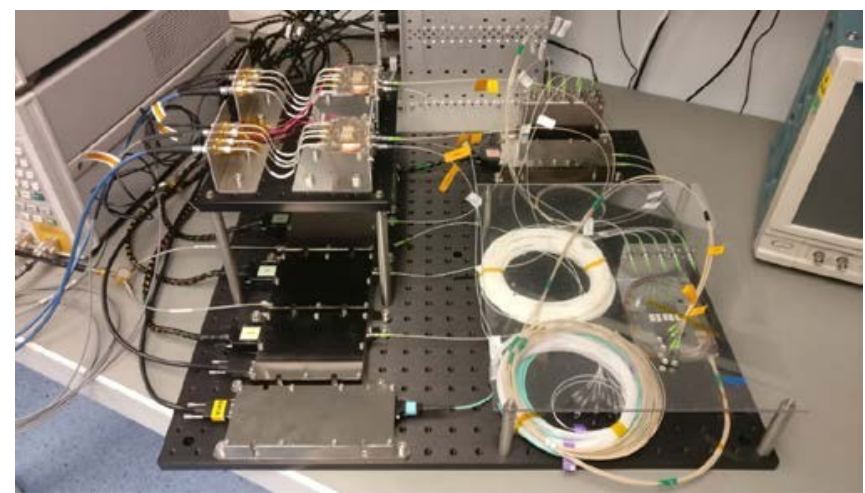

Figure 5 - Advanced Optical Harness during subsystem tests

detect and remove interference in the amplitude, time and frequency domains.

Other features of the advanced L-band instrument include the centralized distribution of the local oscillator, the sampling clock and the calibration signals over an optical harness.

\section{L-BAND RECEIVER BREADBOARDING}

The breadboarding of two receivers of the advanced L-band radiometer has been completed, and are now undergoing endto-end tests. The two units (Fig.4 left) are dual-polarization receivers with an equivalent noise temperature of $130 \mathrm{~K}$ at the antenna plane (190 K in SMOS). The receivers provide high level of out-of-band rejection through sharp band-pass cavity filters (Fig.4 right). The output of the receivers are the 1-bit sampled in-phase and quadrature components of the horizontal and vertical signals, and the power level of each of these (Power Measurement Signals or PMS). The sampling of the signals is performed at a higher rate than in SMOS to partially recover the loss of sensitivity due to the 1-bit sampling. All receiver outputs are sent to the correlator over an optical harness. The units also receive the local oscillator, sampling clock and calibration signals through the optical harness.

\section{OPTICAL HARNESS BREADBOARDING}

While in SMOS the Calibration Signals (CAS) are generated through several overlapped distribution trees, the advanced
L-band instrument would follow a centralized approach. Similarly, in SMOS the local oscillator (LO) is generated in several units frequency locked to a common low frequency reference, the sampling clock (CLK), while in the future radiometer the local oscillator would also be centralized. The breadboarding of an optical harness using wavelength multiplexing to realize the centralized distribution of the CAS, the LO and the CLK as well as the downlink of the measurements from all the receivers to the correlator has been performed (Fig.5). The optical harness has the components performing the optical-to-electrical conversion inside the receiver housing, including the demultiplexing of the three uplinked signals. The optical harness has been already tested together with the individual advanced receivers and will now undergo the final baseline correlation tests. The paper will present the test results.

\section{ADVANCED CORRELATOR CONCEPT}

The breadboarding of the core functionalities of the correlator unit that would be embarked on the advanced L-band radiometer has also been started. The first task is devoted to the definition and preliminary testing of the RFI filtering techniques. For this purpose a simulator has been produced that generates different kinds of interfering signals (pulsed and continuous wave, frequency and amplitude modulated in several ways). These signals are then provided to software simulators of the correlator RFI filters for the assessment of their performance. In a second step, the selected correlator design will then be implemented in using Field Programmable Gate Array (FPGA) technology. The fabricated breadboard is expected to be integrated with the receivers and optical harness in future activity for end-to-end system tests. The results available at the time of the conference of the correlator unit breadboarding will be presented.

\section{EXPECTED PERFORMANCE OF THE ADVANCED L-BAND RADIOMETER MISSION}

The advanced L-band radiometer would have an incidence angle range notably larger over a wider swath than SMOS (Fig.2) improving the quality of the data products over a reduced revisit time of about 2 days (3 days in SMOS). With a size similar to that of SMOS (i.e. about $8 \mathrm{~m}$ ), a spatial resolution of $26.6 \mathrm{~km}$ would be obtained (40.6 km in SMOS) at boresight. This major improvement results from a combination of the widening the alias-free field of view, the hexagonal array geometry and the nadir pointing. The advanced L-band radiometer would achieve a snapshot sensitivity of $1.25 \mathrm{~K}$ over land (2.37 K in SMOS) and $0.86 \mathrm{~K}$ over ocean $(1.72 \mathrm{~K}$ in SMOS). Due to the much larger field of view and the parallel acquisition of the two polarisations, many more snapshots (154 instead of 36 in SMOS) would be acquired for every pixel. This would make the effective radiometric sensitivity of the advanced instrument over a full 


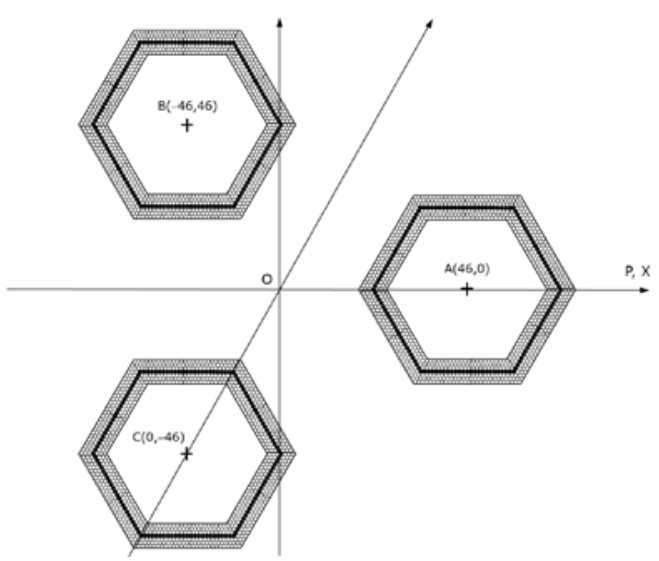

Figure 6 - Formation Flying L-band Aperture Synthesis (FFLAS) concept consisting of three advanced L-band radiometers.

pass 4 times better than that of SMOS $(0.1 \mathrm{~K}$ over land instead of $0.4 \mathrm{~K}$, and $0.07 \mathrm{~K}$ over ocean instead of $0.29 \mathrm{~K}$ ).

\section{ROADMAP TOWARDS A VERY HIGH SPATIAL RESOLUTION L-BAND MISSION}

In order to achieve a spatial resolution of $10 \mathrm{~km}$ it is proposed to fly a formation of three of the described advanced L-band radiometers (Fig.6). The three spacecraft would occupy the vertices of an equilateral triangle and would maintain such formation throughout the orbit. Optical links would be used to send the measurements across the constellation. The CAS, LO and CLK would be generated in one of the three instruments and sent to the other two. Radiofrequency and optical means for maintaining the formation would be required in addition to precise relative positioning through the use of Global Navigation Satellite Signals (GNSS).

ESA has started a study of Formation Flying L-band Aperture Synthesis (FFLAS). The results of the FFLAS study available by the date of the conference will be presented.

\section{CONCLUSION}

The background on the user needs for continued L-band observations and the key lessons learnt from SMOS have been described. From these, the improvements of a future advanced L-band instrument have been identified. The breadboarding activities undertaken by ESA in relation to the antenna, receiver and correlator have been introduced, as well as a roadmap to fulfil user requirements have been given.

\section{REFERENCES}

[1] Mecklenburg S., Drusch M., Kaleschke L., RodriguezFernandez N., Reul Nicolas, Kerr Y., Font J., Martin-Neira M., Oliva R., Daganzo-Eusebio E., Grant J. P., Sabia R., Macelloni G., Rautiainen K., Fauste J., De Rosnay P., Munoz-Sabater J., Verhoest
N., Lievens H., Delwart S., Crapolicchio R., De La Fuente A., Kornberg M. (2016). ESA's Soil Moisture and Ocean Salinity mission: From science to operational applications. Remote Sensing of Environment, 180, 3-18. http://doi.org/10.1016/j.rse.2015.12.025

[2] Kaleschke, L., X. Tian-Kunze, N. Maßß, M. Maekynen, and M. Drusch: Sea ice thickness retrieval from SMOS brightness temperatures during the Arctic freeze-up period, Geophys. Res. Lett., doi:10.1029/2012GL050916, 2012.

[3] Rautiainen, Kimmo \& Parkkinen, Tiina \& Lemmetyinen, Juha \& Schwank, Mike \& Wiesmann, Andreas \& Ikonen, Jaakko \& Derksen, Chris \& Davydov, Sergei \& Davydova, Anna \& Boike, Julia \& Langer, Moritz \& Drusch, Matthias \& Pulliainen, Jouni. (2016). SMOS prototype algorithm for detecting autumn soil freezing. Remote Sensing of Environment. 180. 10.1016/j.rse.2016.01.012.

[4] Nicolas Reul, Joseph Tenerelli, Bertrand Chapron, Doug Vandemark, Yves Quilfen, and Yann Kerr, "SMOS satellite L-band radiometer: A new capability for ocean surface remote sensing in hurricanes", Journal of Geophysical Research, vol. 117, C02006, doi:10.1029/2011JC007474, 2012.

[5] Ocean surface wind speed derived from SMOS, http://www.esa.int/ESA_Multimedia/Images/2019/10/Ocean_surfa ce_wind_speed_derived_from_SMOS.

[6] Raffaele Crapolicchio, Emiliano Capolongo, Alberto Bigazzi. (2016). Sun L-Band Brightness Temperature Estimate from Soil Moisture and Ocean Salinity (SMOS) Mission: a Potential New Space Weather Application for SMOS Data. ESA Living Planet Symposium, May 2016.

[7] Kerr, Yann \& Al-Yaari, Amen \& Fan, Lei \& Wigneron, JeanPierre \& Mialon, Arnaud \& Al Bitar, Ahmad \& Bousquet, Emma \& Richaume, Philippe \& Rodriguez-Fernandez, Nemesio \& Cabot, Frangois \& Miernecki, Maciej. (2019). After Almost 10 Years in Orbit: First Glance at Synergisms and New Results. 6154-6157. 10.1109/IGARSS.2019.8900227.

[8] Font, Jordi \& Jacqueline, Boutin \& Reul, Nicolas \& Spurgeon, Paul \& Ballabrera, Joaquim \& Chuprin, A. \& Gabarro, C. \& Gourrion, Jérôme \& Guimbard, Sebastien \& Hénocq, Claire \& Lavender, Samantha \& Martin, Nicolas \& Martinez, Justino \& Mcculloch, Mike \& Meirold-Mautner, Ingo \& Mugerin, César \& Petitcolin, François \& Portabella, M. \& Sabia, Roberto \& Barcelona, Smos. (2012). SMOS first data analysis for sea surface salinity determination. International Journal of Remote Sensing. 34. 10.1080/01431161.2012.716541.

[9] https://earth.esa.int/web/guest/missions/esa-operational-eomissions/smos/news/-/asset publisher/8pPI/content/smos-joinsforces-with-top-weather-forecasting-system

[10] Summary of "ECMWF/ESA workshop on using low frequency passive microwave measurements in research and operational applications", 4-6 December 2017.

[11] "White paper on L-band radiometry for earth observation: status and achievements"; D-02 of the "Low Frequency Passive Microwave User Requirement Consolidation Study", ESA ITT AO/1-8731, 5 September 2018, Issue 3 